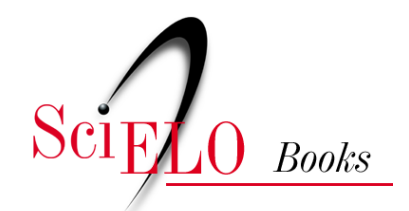

\title{
Crônicas, cantos e outras críticas do sujeito cancional
}

\author{
Leonardo Davino de Oliveira
}

\section{SciELO Books / SciELO Livros / SciELO Libros}

OLIVEIRA, L.D. Crônicas, cantos e outras críticas do sujeito cancional. In: WERKEMA, A.S., ROCHA, F.C.D., and OLIVEIRA, L.D., eds. Literatura brasileira em foco VIII: outras formas de escrita [online]. Rio de Janeiro: EdUERJ, 2018, pp. 148-166. ISBN 978-85-7511-487-2.

https://doi.org/10.7476/9788575114872.0010.

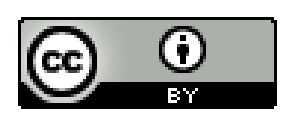

All the contents of this work, except where otherwise noted, is licensed under a Creative Commons Attribution 4.0 International license.

Todo o conteúdo deste trabalho, exceto quando houver ressalva, é publicado sob a licença Creative Commons Atribição $\underline{4.0}$.

Todo el contenido de esta obra, excepto donde se indique lo contrario, está bajo licencia de la licencia $\underline{\text { Creative Commons }}$ $\underline{\text { Reconocimento 4.0. }}$. 
Leonardo Davino de Oliveira

Crônicas, cantos e outras críticas do sujeito cancional 
Desde que a canção popular urbana tomou para si a missão de cantar o Brasil para o Brasil, e isso se afirma enquanto projeto coletivo e sistemático exatamente no momento em que as forças de repressão e censura avançam pela década de 1960, apresentar cronisticamente a realidade sociopolítica brasileira passou a ser um eixo temático incontornável, com o cancionista assumindo muitas vezes o lugar de intelectual da cultura.

Neste meio século dos Festivais da Canção e da Tropicália, este ensaio apresenta uma leitura justaposta de duas canções emblemáticas do período: "Alegria, alegria" de Caetano Veloso - 4 lugar no III Festival da Música Popular Brasileira (1967), TV Record; e "Pra não dizer que não falei das flores" de Geraldo Vandré - $2^{\circ}$ lugar no III Festival Internacional da Canção Popular (1968), TV Globo.

Opero com uma concepção mais ampla de crônica, que permite entender a atuação dos cancionistas como críticos dos variados e complexos aspectos da vida: do engajamento ao desbunde, do político ao banal. O caráter cronístico, que dá conta de acontecimentos contextuais, caracteriza muitas da chamada "canção de protesto" do período observado, em especial entre 1964 e 1968, o que exigirá dos cancionistas certos malabarismos semânticos e formais, a fim de fu- 
gir da censura imposta pela Ditadura Militar. A crônica desliza dos jornais para o corpo, para a voz desses cantores intelectuais críticos da situação do estado de coisas no Brasil.

Originariamente, de vida curta, a crônica se eterniza na memória afetiva dos ouvintes de canção popular e frequentadores dos icônicos Festivais da Canção que marcam a época e definem o gosto cancional do brasileiro de classe média e universitária, e que tem por objetivo a conscientização das massas e a formação de um novo público consumidor. "A morte, o destino, tudo, a morte e o destino, tudo / Estava fora do lugar, eu vivo pra consertar", canta o sujeito de "Disparada" (1966), de Théo de Barros e Geraldo Vandré. Retorna aqui o que Antônio Cândido, em seu artigo "A vida ao rés-do-chão" (2003), identificou como sendo a relação de proximidade estabelecida entre o cronista e o leitor. Ou o ouvinte, no caso de canções cronísticas, empenhadas em ajudar a estabelecer ou restabelecer a dimensão das coisas e das pessoas. A validade da crônica, assim, é estendida e ressignificada afetivamente para o tempo enquanto duram os temas urgentes presentes no plano discursivo dessas canções reflexivas, servindo, igual ao caso da canção "Pra não dizer que não falei das flores", à mobilização e comoção coletiva: das passeatas estudantis de 1977 à campanha pelas Diretas já (1984), passando pelos enterros de vítimas da Ditadura Militar, em destaque: o jornalista Vladimir Herzog (1975) e o operário Santo Dias da Silva (1979).

A distância de postura entre os sujeitos cancionais de cada canção aparece expressa desde os primeiros versos. Enquanto o sujeito da canção de Caetano Veloso canta um "caminhando" contrário ao que o vento, o espírito do tempo (zeitgeist) exige, a saber, o engajamento político do indivíduo nas lutas sociais, o sujeito da canção de Geraldo Vandré convoca o "povo" para seguir essa canção (esse ar) da época. "Olha que a vida tão linda se perde em tristezas assim / 
Desce o teu rancho cantando essa tua esperança sem fim / Deixa que a tua certeza se faça do povo a canção / Pra que teu povo cantando teu canto / Ele não seja em vão", canta o sujeito de "Porta-estandarte", de Geraldo Vandré e Fernando Lona, em uníssono com o sujeito de "Caminhando".

Se canção é sopro, é ar, o sujeito da canção "Pra não dizer que não falei das flores" convida ao canto coral, crente de que o empenho deve estar no coletivo, nas passeatas que reuniam jovens exigindo mudanças nas estruturas antigas de nosso sistema político. Sublinhe-se que Vandré mais tarde iria rejeitar os usos políticos de sua canção, afirmando que menos do que uma "música de protesto", "Caminhando" seria uma "canção de amor", no máximo, "crônica da realidade", "canção expiatória", "música de angústia" (Nuzzi, 2016).

Fato é que desde o título o sujeito de "Caminhando", ao se referir às "flores", está, por metonímia, evocando os desbundados, marginais, alienados adeptos do slogan "paz e amor", e que, dirá o sujeito mais adiante, "acreditam nas flores vencendo o canhão". Lembremos que a imagem do hippie estadunidense serviu de modelo para a dicionarização do desbundado entre nós: cabelos longos, roupas largas, uma flor em uma das mãos e o símbolo "paz e amor" na outra mão. Seria um gesto do cantor "engajado" convocando os "alienados" para juntarem-se em canto? Mais adiante o mesmo sujeito convocará os "soldados armados, amados ou não" a também compor esse coro empenhado num país melhor. Ao resguardar-se na afirmação "pra não dizer que não falei das flores", o sujeito antecipa-se a qualquer acusação futura de descaso para com os desbundados.

O sujeito de "Alegria, alegria" canta o presente imanente e constituinte em contraposição ao desejo de futuro, transcendente, ordenador (externo e superior). Nesse sentido, enquanto o sujeito de Vandré convida, o sujeito de "Alegria, alegria" vai fazendo, ex- 
perimentando. Ambos em suas formas contínuas: "Caminhando...". Um buscando a união, a conjunção pelas semelhanças no desejo de futuro melhor, o outro se despojando de valores antigos de controle da identidade social.

O sujeito de Caetano está na rua, é nômade e não se furta do enfrentamento. Ele adere incondicionalmente ao real e prefere afirmar mais a individualidade, sinônimo de singularidade na multidão, do que ser "massa", facilmente controlada e manipulável. O desbundado se via nessa encruzilhada: mudar o mundo ou "curtir um barato"? Diferente da esquerda armada, os desbundados não pretendiam tomar o poder, ou impor um modelo de sistema melhor. Os desbundados queriam cair fora de todo e qualquer sistema. Nas palavras do cancionista,

desbundar significava deixar-se levar pela bunda, tomando-se aqui como sinédoque para 'corpo' a palavra afro-brasileira que designa essa parte avizinhada das funções excrementícias e do sexo (mas que não se confunde totalmente com aquelas nem com este), sendo uma porção exuberante de carne que, não obstante, guarda apolínea limpeza formal (Veloso, 1997, p. 469).

A fuga pelo misticismo, orientalismo, terapias alternativas, psicologia corporal, sexualidade libertária e ecologia regia a ética dos desbundados. Fuga, nesse caso, é mais o reconhecimento do fracasso das velhas formas de viver e menos uma recusa do enfrentamento dos problemas. Urgia, portanto, enfrentar a patrulha ideológica e liberar a canção e as vozes (a polifonia da multidão), eis a utopia que a Tropicália ousou engendrar.

Os estudantes do TUCA, considerados os mais politizados entre os frequentadores de festivais, não se conformavam que Caetano e Gil não assumissem uma atitude clara de reação ao militarismo e ainda demonstrassem no palco uma certa falta de virilidade que não se coadunava com quem fosse contra a dita- 
dura. A postura máscula de Vandré, um dos ídolos dessa facção, era o oposto (Mello, 2003, p. 277).

Essa Macheza vandreniana simbólica se sustenta em versos como "Meu amor foi embora / Quem é homem não chora / Mas eu vou viver a chorar", de "Quem é homem não chora" (Geraldo Vandré e Vera Brasil); e "O terreiro lá de casa / Não se varre com vassoura / Varre com ponta de sabre / Balas de metralhadora / Quem é homem vem comigo / Quem é mulher fique e chora" ("Cantiga Brava", Geraldo Vandré). Sem esquecer o antológico "Eu venho lá do sertão e posso não lhe agradar / Aprendi a dizer não, ver a morte sem chorar", de "Disparada" (Théo de Barros e Geraldo Vandré).

Ao instar a alteridade, o sujeito tropicalista afirma aquilo que Virgínia Woolf (2014, p. 139), citando Coleridge, inferiu ao pensar que as grandes mentes são andróginas:

É quando ocorre essa fusão que a mente é fertilizada por completo e usa todas as suas faculdades. Talvez uma mente puramente masculina não consiga criar, do mesmo modo que uma mente puramente feminina [...]. [Coleridge] quis dizer, talvez, que a mente andrógina é ressoante e porosa, que transmite emoções sem empecilhos, que é naturalmente criativa, incandescente e indivisa.

Daí que, enquanto "ela pensa em casamento", ele "bebe uma coca-cola e nunca mais foi à escola", reverberando os versos de "O seu amor" (Gilberto Gil), "O seu amor / Ame-o e deixe-o livre para amar / Ir aonde quiser", e desfazendo o coro fascista que dizia "Brasil, ame-o ou deixe-o".

Menos coletivista (povo) e mais mutante (multidão), a mensagem tropicalista calcada no confronto com o espectro do projeto populista autoritário não absolve o ouvinte das responsabilidades diante do processo histórico e sabe que "conduzir" o povo é tarefa dos 
instrumentos do controle do Estado opressor. Ao tropicalista coube compreender a necessidade da iniciativa individual. Por tropicalista entenda-se "aquele que está livre de amarras políticas tradicionais e por isso pode reagir contra a opressão e estreiteza com gestos límpidos e criadores" (Veloso, 1997, p. 319). Sem fé no poder emancipador do "povo" que "caminhando e cantando" segue a canção, o sujeito de "Alegria, alegria" crê na potência da autonomia responsável do indivíduo em meio à multidão.

Ao mesmo tempo, o namoro com o mercado, com a cultura de massa sempre foi o calcanhar de Aquiles da Tropicália. "Ela nem sabe até pensei em cantar na televisão", diz o sujeito de Caetano, confessando para nós ouvintes o desejo inconfessado a "ela", a que faz o sujeito desacelerar o ritmo do caminhar. O desejo de uma arte total, à la Hélio Oiticica, mobiliza o sujeito de "Sem lenço, sem documento" que quer fazer uso da televisão - instrumento de comunicação de massa a serviço da propaganda do golpe militar, e que incomodava bastante determinado setor da esquerda de elite, atenta às reivindicações dos estudantes e operários de então - para propagar as utopias da liberdade e da expressão dos movimentos libertários e contraculturais.

Naquele contexto, tomar uma Coca-cola era uma subversão à lógica da esquerda nacionalista. $\mathrm{O}$ refrigerante imperialista é bebido pelo sujeito que devora as influências estadunidenses na cultura brasileira. Cabe reforçar: o sujeito de "Alegria, alegria", deste modo, “por que não?", nega a mediação e o mediador, seja de direita, seja à esquerda. Ele é representante de si, dono de uma experiência real, autêntica, própria, subjetiva, portanto, excluída da força homogeneizante dos corpos, do condicionamento às estruturas estabelecidas. Ao assumir este caminho não mediado, o sujeito da canção desvencilha-se dos discursos de opressão dos quais a democracia re- 
presentativa parece marcada. Para ele, as desobrigações ideológicas pré-fabricadas e, portanto, também promotoras do empobrecimento da experiência, da redução da experiência a zero, possibilitam a resistência do indivíduo forçado ontologicamente a ser massa, figura vazia de pura obediência. Assim, o que Roberto Schwarz (2012) lê como "apolítico" é, posso arriscar, um gesto radicalmente político e, consequentemente, calcado numa utopia própria das esquerdas, para todos. Vejamos.

$\mathrm{O}$ "sol de quase dezembro", abrasador, desdobra-se na imprensa da contracultura $O$ Sol, jornal de resistência ao golpe militar e que circulou entre setembro de 1967 e janeiro de 1968. O sujeito de "Alegria, alegria" está impregnado das notícias desse jornal, ao mesmo tempo em que se contamina de rua, errância e vagabundagem. Por estar alegre, ele persevera, diz sim à vida, apesar de condenada (contraditória, adversa) pelo contexto político.

Enquanto o sujeito de Vandré canta a restituição da identidade nacional, o outro canta a singularidade de um fragmento da entidade brasileira. Para este não cabe mais restaurar, e sim criar, inventar, engendrar um novo país. Nesse sentido, "Alegria, alegria" percorre o caminho inverso de "Caminhando". Das duas marchas, esta acredita (ingenuamente?) no retorno da segurança pré-golpe e na estabilidade ilusória por vir. "Alegria, alegria", ao contrário, se lança na realidade urbana e múltipla para estilhaçar a confiança nas instituições (Estado e religião), representadas na canção pelo casamento, pela imprensa, pela escola. Aqui o sujeito atravessa a cidade sufocada de "tantas notícias" massacrantes e desestabilizadoras da individualidade, na outra há a crença na igualdade catártica entre as pessoas que serão guiadas pelo sujeito da canção que vive para consertar "a morte, o destino, tudo [que] estava fora do lugar". 
Ao desacreditar, o sujeito da canção de Caetano Veloso, para "seguir vivendo", precisa ir indo; enquanto que o sujeito da canção de Vandré segue crendo no poder aglutinador, amparando-se noutro, delegando ao coletivo as ações que urgem emancipação. Consequentemente, o sujeito de "Alegria, alegria" inventa gestos inapreensíveis pelo sistema paternalista e tirano, colonialista e imperialista. Dito de outro modo era preciso superar o otimismo patriótico, adotando certo pessimismo afirmativo, base da negatividade tropicalista, para que o desmascaramento social e a multiplicidade de dicções e tensões impulsionassem mudanças profundas na motivação de ser brasileiro. Com este projeto de afirmação de uma terceira via, Caetano confundiu não apenas as forças repressoras de direita, mas também os até então colegas à esquerda. Isto porque o sujeito de Caetano Veloso não diz como deve ser feito, mas impele à ação, ao movimento, à experimentação, deixando o ouvinte livre para trilhar o próprio caminho.

Há um misto de ingenuidade e crueldade no sujeito que diz "quem sabe faz a hora", como se as possibilidades e oportunidades para fazer "acontecer" fossem iguais para todos os brasileiros. E como se a "revolução" fosse apenas uma questão de "vontade". Essa alusão à igualdade entre as pessoas nega a multiplicidade da multidão. É justamente desse todos-povo que o sujeito de "Alegria, alegria" vai se descolar, buscando percorrer caminho próprio de dor e delícia, desviando-se tragicamente do controle do Estado.

Se nas canções de Vandré o conteúdo político supera a tríade solar bossa-novista - flor, amor e dor - e glosa o "morro" e o "sertão", não deixa de ser curioso como isso contamina também o sujeito de Caetano Veloso que vai rimar "Brasil" e "fuzil", em detrimento do nacionalista "anil”. No entanto, a questão posta pela antropófaga Tropicália será: o que é raiz num país de culturas transplantadas? 
Outro ponto: descolar-se dessa canção cujo sujeito cancional toma para si a missão de "formar ideologicamente" o povo-ouvinte. Isso porque nas canções tropicalistas de que "Alegria, alegria" faz parte o empenho do sujeito é com a liberdade individual e a desconfiança do conceito "povo", "marchando indecisos cordões" à espera do guia messiânico mimetizado pelo sujeito de "Caminhando". Messias também evocado e projetado noutras canções, Vandré, por exemplo, na figura do "boi" que se torna "cavaleiro" e que, travestido de "boiadeiro", salvará o "nordestino": "Bem no fundo do coração / Guardo há tempos um cavaleiro / Que ainda vou mandar pro norte / Vestido de boiadeiro / [...] / E há um mundo inteiro / Que espera ouvir falar / De um bravo cavaleiro / Que bem soube se guardar / Para um dia lá no sertão / E no mar e em teu coração / Sertanejo ou jangadeiro / Trazer paz para o Norte inteiro" ("O Cavaleiro", de Geraldo Vandré e Tuca).

Em Caetano Veloso, mediação e representatividade são problematizadas quando o cancionista se depara com a ação de Paulo Martins, personagem do filme Terra em transe do cineasta Glauber Rocha. Lembremos: Paulo Martins, político à esquerda e poeta, tapa a boca de um líder sindical e diz: "Estão vendo quem é o povo? Um analfabeto, um imbecil, um despolitizado". A leitura que Caetano faz da cena é, aliás, duramente criticada por Roberto Schwarz no ensaio "Verdade tropical: um percurso de nosso tempo" (2012), em que o autor apresenta uma análise do livro de memórias de Caetano Veloso (1997). Escreve o cancionista: "quando o poeta de Terra em transe decretou a falência da crença nas energias libertadoras do 'povo', eu, na plateia, vi, não o fim das possibilidades, mas o anúncio de novas tarefas para mim" (p. 116). A catarse medicamentosa, veneno que cura, experimentada por Caetano fará o tropicalista romper com qualquer transcendência consoladora, bem como com o papel 
de mediador incorporado pelo "homem da terra" que persiste e luta contra a tirania e exploração latifundiária: "Eu que plantei muito e não tenho nada / Ouço tudo e calo na caminhada [...] Quanto mais eu ando, mais vejo estrada / Mas se eu não caminho eu não sou é nada" ("Ventania", de Geraldo Vandré e Hilton Acioli).

Para Rafael Julião (2017, p. 367),

a representação de povo brasileiro feita nesse universo político-ideológico (e não o povo em si) é posta em xeque no filme de Glauber, o que leva Caetano a rever aquelas posiçóes, que ele já vinha olhando com desconfiança desde antes, conforme exemplifica o artigo de 1965, em que defende a bossa nova a despeito do nacionalismo anti-imperialista de Tinhorão, ou contra as propostas de Augusto Boal no mesmo ano.

Por suavez, Roberto Schwarz (2012,p.77) escreve que "do ponto devistadaesquerda,acena - umainvençãoartísticadeprimeiraforçaera um compêndio de sacrilégios, fazendo uma espécie de chacota dolorosa das certezas ideológicas do período". Schwarz parece não compreender que para Caetano o gesto do poeta no filme se desdobrava no verso tropicalista "Não temos tempo de temer a morte", ou seja, o que era uma metáfora também era diagnóstico e precisava ser terapêutico.

$\mathrm{Na}$ única vez em que a palavra "alegria" do título aparece no plano discursivo-literário o que chama a atenção é que, ao invés de surgir dobrada, a "alegria" vem acompanhada de "preguiça" - pergunto: macunaímica? De repetir velhas formas de enfrentamento? A canção que vinha sendo executada em ritmo acelerado, condizente com o ir indo do sujeito cancional, desacelera, descontinua o caminhar se espreguiçando, o sujeito cancional alonga as vogais no exato momento em que o sol bate na banca de revista revelando o Sol - o jornal contracultural, contra a cultura do mesmo, do sufoco 
ideológico e das utopias. Esse procedimento rítmico também se dará quando o sujeito evocar "ela", a que "pensa em casamento" - "ela nem sabe até pensei / em cantar na televisão / o sol é tão bonito" ratificando a apreciação da luminosidade em tempos sombrios: ela/ televisão/sol, trindade promotora da singularidade do sujeito tropicalista no mundo de "amores vãos".

Sobre o título, Caetano (1997, p. 166) comenta que "havia a distância necessária para a crítica — para mim, uma condição da liberdade —, mas havia a alegria imediata da fruição das coisas”. E completa escrevendo que "essa consciência da alegria assim situada me levou a eleger como título (sem, contudo, incluir na canção) o cordão 'alegria, alegria!', que o animador de TV Chacrinha emprestara do bom cantor de samba-jazz em vias de aderir a um comercialismo vulgar (mas nem por isso menos delicioso) Wilson Simonal” (p. 166).

Destaquem-se ainda os versos "Sem lenço sem documento / Nada no bolso ou nas mãos / Eu quero seguir vivendo, amor / Eu vou" que fazem uma citação direta e desconstrutiva de Jean-Paul Sartre (1984, p. 183) quando este escreve que o que ama em sua loucura é que ela sempre o protegeu contra as seduções da elite: "nunca me julguei feliz proprietário de um talento: minha única preocupação era salvar-me - nada nas mãos, nada nos bolsos - pelo trabalho e pela fé". Ao mesmo tempo, a citação ajuda o sujeito caetânico a rejeitar também as flores dos hippies estadunidenses, já que suas mãos seguem vazias, livres. Este jogo lúdico e intertextual entre o testemunho e o questionamento problematiza os conceitos de arte engajada, participativa, empenhada, posto que "é a disseminação da luz que permite o esclarecimento de diversas questões naquele momento candentes. A tópica do desengajamento para poder enxergar o mundo sem filtro das posições preconcebidas era uma delas" (Tatit, 
2001, p. 189), reforçando o caráter cronístico — as marcas do tempo - dessas canções.

Por sua vez, os versos emparelhados - "saber", "acontecer" - do refrão de "Caminhando" apontam a intenção de unificar, ou seja, as rimas emparelhadas figurativizam o convite para que cantor e ouvinte sigam em uníssono. Diferentemente de "Alegria, alegria", cujo refrão - “Eu vou, por que não? Por que não?” — funciona mais como uma lírica intimidação do que um convite. Segundo Augusto de Campos (1978, p. 153),

no contexto maior da música popular brasileira, aquele 'Por que não?' do estribilho tomou características de um desabafo-desafio. E foi com esse sentido que o compositor, na primeira apresentação da música, triunfando sobre o desagrado com que um público preconcebido recebera o conjunto acompanhante dos Beat Boys, terminou, ao final, por proclamar, braços abertos à plateia conquistada: 'Por que não?'.

$\mathrm{Na}$ resistência da vida e sua afirmação trágica, um ("Caminhando") crê não ser reativo - porque supostamente convida todos, está aberto à alteridade - e é, o outro ("Sem lenço, sem documento") poderia se pensar reativo, por não se diluir na massa, e não é, posto que promove a alteridade.

Para Marcos Napolitano (2007, p. 127),

a busca constante de referências musicais e culturais revelava as vicissitudes de um artista [Vandré] que, mais do que outros, incorporou a tarefa de criação de uma canção 'de massa', engajada e exortativa, dentro das estruturas do mercado. Essa tarefa era incrementada pela radicalização do quadro político do país, 
que parecia impregnar o trabalho de Vandré mais do que o de outros músicos.

E completa destacando que

a partir de 1967, [Geraldo] tornou-se o músico brasileiro mais identificado com a versão brasileira da 'canção de protesto', superando Nara Leão. Essa mudança de referencial foi causa e efeito da grande popularização da MPB, entre fins de 1966 e 1968, cuja demanda requeria canções mais diretas e exortativas, inspiradas nas formas musicais anteriores à bossa nova (p. 127).

Lembremo-nos dos versos "O mundo foi rodando nas patas do meu cavalo / E nos sonhos que fui sonhando, as visões se clareando / As visões se clareando, até que um dia acordei" ("Disparada", de Théo de Barros e Geraldo Vandré). É esse sujeito esclarecido e desperto que toma para si a tarefa de tocar - aboiar - o levante popular. Mas isso não é manter o povo "gado"? O povo deixa de ser "gado" só porque quem está guiando agora é um sujeito "vindo do povo"?

Se Millôr Fernandes tratou "Caminhando" igual a "Marselhesa brasileira”, a canção repercutiu entre nacionalistas eruditos e militares. Para Tárik de Souza, "a esquerda desdenhava a música, achando-a pejorativamente cartática e desmobilizadora, enquanto a direita representada por militares dissecava ponto a ponto a composição, pedindo a prisão de Vandré pelos jornais por excesso de eficiência mobilizadora" (In Mello, 2003, p. 300). Jairo Severiano (1998, p. 125) lembra que

classificada pelo maestro Lindolfo Gaya como uma guarânia e pelo próprio Vandré como 'um rasqueado de beira de praia', 'Caminhando' mereceu do general Luís de França Oliveira, secretário de Segurança da Guanabara, o seguinte comentário, em entrevista que justificava a sua proibição: 'Pra não dizer que 
não falei de flores' tem letra subversiva e sua cadência é do tipo Mao-Tsé-Tung.

A passividade inebriante no tônus geral do ritmo da canção de Vandré, resultando na incoerência entre o que é dito e o modo de dizer, faz o andamento melódico ser o núcleo duro - a tensão ética e estética - que a distingue de "Alegria, alegria". A busca pela verdade finda por criar fugas da verdade. Tal incoerência será percebida e criticada em sua revolução conservadora tanto por Walnice Nogueira Galvão (1976), para quem "Geraldo Vandré é um especialista" da "Moderna Música Popular Brasileira [que] se caracteriza por uma intencionalidade informativa e participante" (p. 94) e a "esperança na MMPB, significa inação. Esperar significa postergar para o futuro. Vai implícita uma justificação do presente, em função da confiança na autonomia do futuro" (p. 97); quanto por Luiz Carlos Maciel (1968), que em artigo no Correio da Manhã escreveu sobre esse retorno à inércia: "O antimilitarista que cantou e aplaudiu 'Caminhando’ no Maracanãzinho saiu de coração lavado pela purgação de suas reservas agressivas. Quando, de volta pra casa, passou em frente ao Ministério do Exército, olhou-o com menos hostilidade e ressentimento: aliviara sua torturante sensação de impotência” (apud Nuzzi, 2016).

Ou seja, se o sujeito de "Caminhando" diz "vem, vamos embora", sua performance vocal o desdiz. O levante (euforia) proposto é vocalizado por um sujeito estático (disforia). A crítica social se limita ao plano do discurso. Em "Alegria, alegria", no entanto, o componente crítico aparece incorporado também ao ritmo e ao andamento da canção: “Eu vou!”.

A idealização da certeza (da verdade) é marca das canções de Vandré. Em "Vou caminhando" o sujeito diz que "Meu canto e meu riso / Não são pra enganar"; em "Disparada", temos "Se você não 
concordar não posso me desculpar / Não canto prá enganar"; e em "Porta-estandarte", "Deixa que a tua certeza se faça do povo a canção". Essa reiterada rejeição à mentira, ao engodo, à ambiguidade, ao tropo, ao canto das sereias, esse estar a serviço de uma mensagem clara, objetiva, direta, movimenta o sujeito empenhado em "consertar" o mundo. Jogar a certeza para o futuro consola o sujeito "de bem" que aspira ao conforto dominical burguês crente do processo linear e progressivo - não progressista! - da história.

Os sujeitos das canções "Alegria, alegria" e "Pra não dizer que não falei das flores" estão intimamente implicados com os acontecimentos em torno de seus cancionistas. As referências ao Sol e ao "soldado", respectivamente, enchem as canções de veracidade e crônica, mesclam autor, narrador e personagem numa única voz enunciativa. Na segunda, a "nova lição" será ensinada no futuro, na primeira não há lição, não há transmissão de ensino-conhecimento, há vivência. Conforme tentei expor, a linguagem discursiva direta e sua mensagem de significado rapidamente compreensível da segunda são desmentidas pelo ritmo passional e paralisante da canção; enquanto que na primeira há o experimento de uma ética da experiência.

A linguagem abstrata, fragmentada, impregnada do real, com foco mais no significante - esforço reflexivo individual - do que no significado - dado, fechado, transmitido, ensinado - de "Alegria, alegria" evoca o jogo entre identidade e alteridade, conforme entendido na canção de Caetano Veloso: falar de si ("eu vou”) é falar do outro ("vem, vamos embora"), este nós emerge como ponte entre o "eu" e "tu", mas esta ponte se estabelece no gesto mimético que ao outro é dado realizar.

Estamos em 2018. As flores que os artistas plantaram já não lhes pertencem. Os retornos contextuais dessas duas canções as- 
sombram o Brasil de hoje. Sejam nas estruturas messiânicas de "Pra não dizer que não falei das flores", que vai ser cantada, inclusive, em manifestações que pedem a volta da ditadura militar no país, mas também nas homenagens a Marielle Franco, vereadora (mulher, negra, periférica, lésbica) de esquerda executada em alarmante crime político, sejam nas urgências individuais e identitárias, o sufoco ético da década de 1960 ressurge em 2018, semelhante a um retorno do mesmo, carregado de rancor e recalque burguês e religioso: "Sol, a culpa deve ser do sol, que embaça os olhos e a razão", canta Chico Buarque em "Caravanas” (2017). 


\section{Referências}

ADORNO, Theodor. "Palestra sobre lírica e sociedade". In Notas de literatura I. São Paulo: Ed. 34, 2003.

CAMPOS, Augusto de. "A explosão de Alegria, alegria". In Balanço da bossa e outras bossas. São Paulo: Perspectiva, 1978.

CANDIDO, Antonio. “A vida ao rés-do-chão". In Para gostar de ler: crônicas. São Paulo: Ática, 2003.

GALVÃO, Walnice Nogueira. "MMPB: uma análise ideológica”. In Saco de gatos: Ensaios críticos. São Paulo: Livraria Duas Cidades, 1976.

HOLLANDA, Heloisa Buarque de. Impressões de viagem: CPC, vanguarda e desbunde: 1960/70. Rio de Janeiro: Aeroplano, 2004.

JULIÃO, Rafael. Infinitivamente pessoal: Caetano Veloso e sua verdade tropical. Rio de Janeiro: Batel, 2017.

MELLO, Zuza Homem de. A era dos festivais: uma parábola. São Paulo: Ed. 34, 2003.

NAPOLITANO, Marcos. Seguindo a canção: engajamento político e indústria cultural na MPB (1959/1969). São Paulo: AnnaBlume/ FAPESP, 2001.

NUZZI, Vitor. Geraldo Vandré: uma canção interrompida. São Paulo: Kuarup, 2016. 
OLIVEIRA, Leonardo Davino de. Canção: a musa híbrida de Caetano Veloso. Rio de Janeiro: Ibis Libris, 2012.

SARTRE, Jean-Paul. As palavras. Trad. J. Guinsburg. Rio de Janeiro: Nova Fronteira, 1984.

SEVERIANO, Jairo e MELLO, Zuza Homem de. A canção no tempo: 85 anos de músicas brasileiras, vol. 2. São Paulo: Ed. 34, 1998.

SCHWARZ, Roberto. "Verdade tropical: um percurso de nosso tempo". In Martinha versus Lucrécia: ensaios e entrevistas. São Paulo: Companhia das Letras, 2012.

SILVA, Alberto Moby Ribeiro da. Sinal fechado: a música popular brasileira sob censura. Rio de Janeiro: Apicuri, 2008.

TATIT, Luiz. "Alegria, Alegria”. In Análise semiótica através das letras. São Paulo: Ateliê Editorial, 2001.

TINHORÃO, José Ramos. Pequena história da música popular: Da modinha à canção de protesto. Petrópolis: Ed. Vozes, 1974.

VELOSO, Caetano. Verdade tropical. São Paulo: Companhia das Letras, 1997.

WOOLF, Virginia. Um teto todo seu. Trad. Bia Nunes de Sousa e Glauco Mattoso. São Paulo: Tordesilhas, 2014. 